\title{
Presentación de Otros Temas del Número 79
}

\section{Presentation of Other Themes from Number 79}

\author{
Ma. Cristina Fuentes Zurita \\ Universidad Autónoma Metropolitana Iztapalapa, \\ Ciudad de México, México \\ ORCID: https://orcid.org/0000-000I-7230-6103 \\ ISSN: ISSN-0I85-4259; e-ISSN: 2007-9176
} DoI: http://dx.doi.org/I0.28928/revistaiztapalapa/792015/pot/fuenteszuritamc

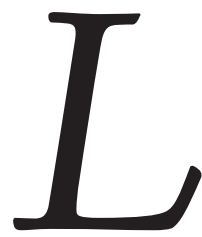

os artículos y reseñas incluidos en la sección de Otros temas de este número 79 de Iztapalapa. Revista de Ciencias Sociales fraguando en el México actual.

Cada uno de estos trabajos tiene el mérito de aportar nuevos elementos y desde diversos ángulos para comprender mejor nuestro presente. Todos ellos resultan de investigaciones comprometidas que aspiran a constituir nuevos escenarios para la reflexión científica, renovados abordajes, fórmulas innovadoras, para ofrecer miradas y acciones orientadas a la construcción de un mundo diferente, fundado en el cambio económico, social y cultural. El lector encontrará un conjunto de análisis críticos, planteados desde distintas corrientes disciplinarias, sobre la situación actual. Estas reflexiones brindan elementos para una visión de conjunto y al mismo tiempo ayudan a vislumbrar nuevas propuestas 
teórico-metodológicas. Los autores aquí reunidos provienen de las ciencias sociales, económicas y las humanidades.

La sección se compone de tres artículos y dos reseñas de libros recientes. En el primero de estos aportes, Héctor Domínguez Ruvalcaba, profesor de la Universidad de Texas en Austin, siguiendo con la línea de investigación sobre masculinidades y violencia, en el artículo "Atisbos a la subjetividad de los victimarios en el cine y el ciberespacio en México" realiza un análisis de las imágenes integradas en la prensa digital, en el cine y en series nacionales. Para ello, en un inicio nos presenta un encuadre sobre los estudios críticos de género y de sexualidad. La exposición está articulada en varios ejes: en el primero aborda los conceptos de misoginia, homofobia y patriarcado, que sirven para comprender la cultura de género de nuestro país y allende sus fronteras. En un segundo apartado el autor muestra ejemplos de diversas posturas homofóbicas y misóginas en torno a diversas noticias que generan discusiones en espacios de conversación abierta en la web. Así, analiza la subjetividad de los usuarios a través de sus respuestas justificadas desde sus registros religiosos o normativos. El tercer apartado se enfoca en los feminicidios de Ciudad Juárez, tomando como insumo el cine, para demostrar las formas de encubrimiento de los culpables que solo permiten observar su crueldad sobre los cuerpos de las víctimas. El último apartado muestra la articulación de una nueva práctica económica que se alimenta de los más pobres y vulnerables, para vender su violencia sobre otros cuerpos.

En este tenor, los investigadores Hada Melissa Sáenz Vela, Luis Gutiérrez Flores (ambos del Centro de Investigaciones Socioeconómicas de la Universidad Autónoma de Coahuila) y Enrique Eliseo Minor Campa (del Consejo Nacional de Evaluación de la Política de Desarrollo Social), en su artículo "Aproximación para analizar el índice de intensidad de la pobreza multidimensional de México", problematizan los métodos de medición utilizados, ya que, de acuerdo con su evaluación, estos no reflejan la profundidad de la pobreza, ni la vinculan a la carencia de derechos sociales como son el acceso a la educación, a la salud, a la vivienda, a la alimentación, etcétera, ocultándose así la complejidad de la situación actual en términos de pobreza.

Recientemente, el Coneval presentó el informe correspondiente a la evolución de la pobreza en el país durante el bienio 2013-2014. Las noticias no son buenas: en 2014 se registran 55.3 millones de mexicanos en condiciones de pobreza, lo que significa que hay 2 millones más respecto de 2012, habiendo crecido también como proporción de la población total. En este contexto, es indudable que todos los esfuerzos académicos encaminados a contribuir con estas mediciones y el desarrollo de 
políticas adecuadas para superar el fenómeno, como el aquí presentado, se tornan sumamente valiosos.

Los autores de este trabajo sobre el índice de intensidad de la pobreza multidimensional presentan un detallado análisis de la medición realizada por el Coneval como un caso particular de la propuesta de Alkire y Foster. Así, confirman la independencia "que supone Coneval entre el ingreso y las carencias, pues la medida de la profundidad de la pobreza se reporta como una medida separada".

En el tercer artículo de Otros temas,"Tensiones políticas en el proceso de movilización-desmovilización del movimiento \#YoSoyı32", Guadalupe Olivier Téllez y Sergio Tamayo abordan la protesta social surgida en 2012 en México. Cabe recordar que ese movimiento al que hace referencia el texto fue iniciado por estudiantes de la Universidad Iberoamericana y luego secundado por otros miles de simpatizantes.

En este trabajo se muestra la dialéctica de los movimientos sociales a partir del estudio del \#YoSoyı32, y en particular se plantean interrogantes acerca de las fuertes escisiones con las que concluyó ese movimiento en enero de 2013. Fue un movimiento social que no logró su objetivo explícito, aun cuando se extendió a decenas de ciudades en todo el país y muchas personas se identificaron con él y se afiliaron. Los autores presentan una amplia discusión teórica sobre el estudio de los movimientos sociales cuyas diversas perspectivas van desde las identidades colectivas y las emociones en la movilización, hasta la falta de compromiso individual para comprender la desmovilización.

En la primera parte del artículo abordan el contexto político de México en el 20I2, describen brevemente una genealogía del movimiento, para posteriormente introducir las tensiones políticas que se desarrollaban internamente. La relevancia del ensayo radica en que documenta con amplitud las contradicciones que surgieron entre las posiciones de los estudiantes de las universidades públicas y las privadas, por ejemplo, en torno a la incorporación de demandas sociales más amplias y no únicamente la democratización de los medios de comunicación. Para ello, utilizan una vasta metodología multidimensional, que incluye entrevistas, revisión y análisis de fuentes diversas, por ejemplo, publicaciones electrónicas, documentales en los sitios de Youtube, Facebook y Twiter en torno a la protesta social.

Por último, los Otros temas de Iztapalapa. Revista de Ciencias Sociales y Humanidades, reiteran el espíritu de debatir y difundir nuevas obras de notoria envergadura, por medio de reseñas. La primera es del libro Ética e internet, de Cess Hamelin, comentado por la experta en el tema Gabriela Barrios. Cess Hamelin es un comunicólogo reconocido a nivel internacional, adscrito a la Universidad de Ámsterdam, preocupado desde los años sesenta por los acuerdos de paz en los medios de comu- 
nicación, y luego también en internet. Recientemente, la Real Academia Belga de Ciencias y Artes lo ha distinguido con el reconocimiento Thinker y en julio 2015, de manera simultánea a la publicación de esta reseña en Iztapalapa. Revista de Ciencias Sociales y Humanidades, la traducción de este libro fue publicada por Siglo XXI Editores de México. Gabriela Barrios ha sido la correctora de la edición en español de la obra en cuestión, nadie mejor para hacer esta reseña. En ella, Barrios nos invita a leer un pensamiento sólido que señala fuertemente a otro basado en la competencia y la falta de empatía que circula en los bits, con el cual no se construirán acuerdos. Lectura imprescindible sobre el lenguaje actual del poder económico.

Al final, y como un cierre alentador, contamos con la reseña del libro "Aquestas son de México las señas". La capital de la Nueva España según los cronistas, poetas y viajeros (siglos del XVI al XVIII), de María José Rodilla León, literata investigadora del Departamento de Filosofía de la Unidad Iztapalapa de la Universidad Autónoma Metropolitana. La reseña es de Miguel Mariñas, de la Universidad Complutense de Madrid, también reconocido medievalista. De acuerdo con Jairo Gómez, el lenguaje es en donde lo objetivo y los hechos pasan por el tamiz de la ficción subjetiva, ya que los mundos se crean en las interpretaciones y muestran que existen otros mundos alternos y posibles. La ficción subjetiva se manifiesta siempre como un complemento a la pura facticidad. Se pueden distinguir los modos de subjetivación afirmativa, como el que logramos leer en esta reseña, creadora de posibilidades de vida, productora de la novedad, de las subjetivaciones negativas, negadoras de ella. La literatura cuenta con diversas formas de construir mundos alternativos, que son las formas de organizar nuestras experiencias y al hablar de versiones diferentes, se posibilita hablar de mundos distintos.

Miguel Mariñas destaca la magnitud de la investigación que alimentó y posibilitó esta obra. Subraya que el libro de Rodilla León ofrece un mundo alternativo al recuperar las formas del habla, del alma, logrando bellos paisajes tejidos de barroco, formados de claro-obscuros, de hilos de luz de sapiencia, erudición y amor por esta ciudad. Juegos de verdad y ficción que nos regalan una escafandra, un prisma maravilloso, un antifaz, un catalejo finísimo que constituyen hoy importantes artefactos en la proyección de futuro. Con esta mirada, y también con los datos ofrecidos en toda esta sección, nos podemos preguntar desde nuestro lugar en el mundo académico, ¿qué mundo queremos crear? 